\title{
FALSIFICACIONES Y ARQUEOLOGÍA: RICARDO LATCHAM, LA ESCRITURA PREHISPÁNICA Y LOS PIRATAS DE GUAYACÁN
}

\author{
FORGERIES AND ARCHAEOLOGY: RICHARD LATCHAM, THE \\ PRECOLUMBIAN WRITING, AND THE GUAYACÁN PIRATES
}

Francisco Garrido \& Carolina Valenzuela ${ }^{B}$

Este artículo aborda el rol de las falsificaciones arqueológicas en la construcción del conocimiento y narrativas sobre el pasado, a partir del presunto descubrimiento de escritura prehispánica por el arqueólogo Ricardo E. Latcham en 1929. Latcham vio en una colección falsificada de alfarería de la cultura "ProtoNazca" el posible descubrimiento de un sistema de escritura prehispánico. El autor publicaría cuatro artículos sobre esta teoría y, algunos años después, un libro de estilo novelístico, aunque presentado como factual. En este artículo se reflexiona sobre las falsificaciones en las colecciones museológicas, las que ponen en evidencia la falibilidad de los expertos, las formas de construcción de conocimiento arqueológico y, en este caso, su derivación en la invención de una realidad histórica.

Palabras clave: Anticuarios, Falsificaciones, Cultura ProtoNazca, Ricardo Latcham, Museo Nacional de Historia Natural.

From the supposed discovery of pre-Hispanic writing by archaeologist Ricardo E. Latcham, this article discusses the role of archaeological forgeries in the creation of knowledge and narratives about the past in 1929 Latcham saw in a forged "Proto-Nazca" culture pottery collection the possible discovery of a pre-Hispanic writing system. Latcham would go on to publish four articles about this theory and, some years later, a novel-like book, but presented as factual. This article reflects on the forgeries in museum collections, which reveal the fallibility of experts, the ways in which archaeological knowledge is built and, in this case, its role in the invention of historical reality.

Keywords: Antiquarians, Forgeries, Proto-Nazca Culture, Ricardo Latcham, National Museum of Natural History.

\section{ANTICUARISMO, ARQUEOLOGÍA Y FALSIFICACIÓN DEL PATRIMONIO CULTURAL}

El estudio de la cultura material del pasado no siempre se ha basado en la investigación de contextos arqueológicos excavados de modo sistemático o de colecciones con un origen bien documentado. En muchos casos la información de proveniencia es dudosa, especialmente en colecciones privadas sin una sistematización científica, lo cual dificulta la interpretación que se pueda realizar sobre el pasado. La arqueología y el anticuarismo han tenido desde el comienzo una íntima relación, desde un legado intelectual común sobre el estudio de la cultura material, particularmente durante el siglo xix. En tal rol, ambas disciplinas se han nutrido constantemente de métodos analíticos y del sustento material de sus análisis, especialmente en lo referente a las interpretaciones sobre los artefactos y sociedades del pasado (Murray 2007: 11-35). En ambos casos sus practicantes requieren de conocimiento especializado con el fin de catalogar, valorar y curar artefactos que se conciben con una certificación de autenticidad. Sin embargo, no todo artefacto cultural del pasado, cuando enfrenta un

A Francisco Garrido, Museo Nacional de Historia Natural. ORCid: 0000-0001-8979-2670. E-mail: francisco.garrido@mnhn. gob.cl

B Carolina Valenzuela, Universidad Autónoma de Chile, Instituto de Estudios Sociales y Humanísticos. ORCID: 0000-00026841-6569. E-mail: carolina.valenzuela01@uautonoma.cl 
criterio de oferta y demanda, puede ser proveído de modo frecuente y contextualizado. Además, la ambigüedad del conocimiento existente sobre colecciones poco comunes o con incipiente investigación puede derivar en clasificaciones erróneas, o bien en el aceptar como originales artefactos que no lo son.

En general, hay diversos tipos de falsificaciones motivadas ya sea por el simple lucro, por orgullo profesional, nacionalismo o prestigio intelectual y académico (Mora 2011: 261-278). Sin embargo, más allá de la intencionalidad o no de una falsificación, lo relevante es que estas se han transformado en un hecho común en museos y colecciones particulares, especialmente cuando no han podido ser examinadas con cuidado por especialistas y no provienen de un contexto arqueológico debidamente certificado y analizado. Dado que las falsificaciones requieren de una amplia red de actores para hacerse efectivas en el mundo académico, han pasado a ser un campo de estudio en sí mismas, ya que ofrecen una muestra del estado del arte de los conocimientos de la época en que fueron fabricadas, de las redes intelectuales, de los debates científicos de que fueron parte y de sus fuentes de inspiración (Mora 2011:276). Incluso se han realizado exposiciones museográficas que destacan el interés de las falsificaciones como objeto de estudio. Ejemplo de ello fue la exposición organizada en 1990 por el Museo Británico: Fake? The art of deception, la cual buscaba capturar la fascinación sobre las falsificaciones, a la vez que proponía una reflexión sobre ellas, al tratarse de objetos con una gran carga emocional, pero a los que nadie quiere ser asociado, demostrando que el experto no es infalible (Jones 1990: 9-11).

Para el caso de los Andes, la producción y comercio de falsificaciones presenta algunas características particulares. De acuerdo con Bruhns y Kelker (2010: 11-16), las falsificaciones de Sudamérica son menos conocidas que las de México o Centroamérica. El desconocimiento foráneo se acentúa en el caso de los artefactos preincaicos, lo cual los hace más difíciles de identificar. Otro factor que dificulta la identificación es que, en general, al arte prehispánico no se le atribuye el mismo mérito que al del mundo clásico, fuente de la civilización europea, lo cual hace menos riguroso el estudio de sus atributos. De hecho, los falsificadores de las antigüedades americanas no tienen el mismo prestigio que los falsificadores de las antigüedades clásicas, por el prejuicio de primitivismo del arte prehispánico. Por otra parte, Bruhns y Kelker (2010: 189-192) consideran que el foco en la nueva his- toria del arte resta protagonismo al estudio de la cultura material, produciendo como resultado generaciones de profesionales con menor conocimiento primario, siendo difícil el diferenciar la pieza real de la falsificación. Esto tendría su impacto en los museos, donde muchos especialistas llamados a identificar la autenticidad de las piezas en sus respectivas instituciones, carecen de herramientas para hacerlo adecuadamente. Incluso para experimentados profesionales de la arqueología, es muy difícil distinguir piezas falsificadas cuando estas no provienen de un contexto arqueológico certificado (Stanish 2009).

En los Andes, los artefactos de alfarería dominan en el mercado de antigüedades y en las colecciones públicas y privadas de arte precolombino. Desde principios del siglo $\mathrm{xx}$, los falsificadores imitaron los diseños propios de la cultura material de los indígenas, pero también inventaron sus propios estilos haciendo creer al público que se trataba de antigüedades, como en el caso del estilo "Nueva Quimbaya" en Colombia, o el conocido caso de las piedras de Ica en 1966 (Bruhns \& Kelker 2010: 109-111). Si bien el mercado de antigüedades andinas falsificadas tiene más de un siglo de existencia, en años recientes se ha intensificado gracias al surgimiento de sitios de ventas online y la sofisticación de reproducciones prehispánicas de alta calidad manufacturadas por artesanos locales (Stanish 2009). Más allá de su presencia en colecciones privadas o museográficas, el rol de estas falsificaciones museográficas en debates académicos ha sido de gran relevancia. Este último tema lo examinaremos a través del caso del presunto descubrimiento de escritura prehispánica basado en el análisis de una colección falsificada, la cual fue adquirida por el Museo Nacional de Historia Natural de Chile en el año 1929.

\section{EL PRESUNTO DESCUBRIMIENTO DE ESCRITURA EN LOS ANDES PREHISPÁNICOS}

En el panorama de la investigación arqueológica actual no se conoce ninguna sociedad prehispánica de los Andes que haya desarrollado un sistema de escritura alfabético o ideográfico. De hecho, los conquistadores y evangelizadores españoles ya se preguntaban sobre este tema, especulando sobre la existencia de signos alfabéticos que vinculasen las culturas locales con el Viejo Mundo. Un ejemplo de aquello lo observamos 
en esta cita del religioso Gregorio García, a principios del siglo xviI:

\begin{abstract}
Averiguando yo en el Perú, si havia algunas antiguallas, o congeturas, por donde constase haver tenido los Indios letras, fui informado de un Español, que trataba en las Minas de Çamora (...) està una Peña alta con un pico, à bordo salido fuera, en cuia frente estan esculpidos quatro renglones, cada uno de vara i media de largo, cuias letras parecen Griegas (García 1729: 189).
\end{abstract}

Gregorio García suponía que los nativos del Perú podrían haber tenido un sistema alfabético que fundamentaría un supuesto origen griego de los pueblos del Nuevo Mundo. Ante las dudas de quienes cuestionaban la existencia de sociedades andinas con escritura en su época, García explica que tal vez podrían haberlas perdido en algún diluvio, así como los griegos las perdieron en algún tiempo, como lo dice Platón, o bien por guerras, como también habría sucedido en España. Sin embargo, las suposiciones del religioso quedaron en el campo de la imaginación y carecen de fundamento histórico.

En los Andes prehispánicos, el sistema de registro más conocido es el khipu, el cual fue extendido a gran escala por el Imperio Inca para fines de contabilidad de la producción dentro del Estado. Su sistema estaba basado en nudos atados a cuerdas de diversos colores, tipos de nudos y jerarquía de niveles de información. Estos podían registrar números, los cuales requerían de un administrador especial o quipucamayoc con el fin de descifrar el resto del contenido del mensaje dado su carácter semasiográfico (Urton 2017). En tal sentido, los khipus cumplían una función de registro contable y de recurso nemotécnico para manejar la producción y el sistema de tributación en el Estado Inca, que se fundaba en turnos de trabajo. Fuera de aquella modalidad de registro, que fue fundamental para la administración del Imperio Inca, cuyo origen se remonta al Período Medio (500-1000 DC) dentro del Imperio Wari, no existe evidencia de ningún otro sistema escritural en el pasado prehispánico sudamericano (Salomon 2013, Urton 2014).

Tal convicción actual sobre la inexistencia de escritura alfabética prehispánica en los Andes ha pasado por diversas etapas de debate y discusión, en donde varios autores propusieron la posibilidad de que ciertas representaciones iconográficas prehispánicas fuesen parte de sistemas de escritura complejos esperando a ser descubiertos y descifrados. En general, esto va de la mano con la noción y prejuicio de que las sociedades preliterarias serían ahistóricas, desde una lógica colonialista que las asocia a falta de progreso, socialmente estáticas y barbáricas (Murray 2013: 15-16). Por ello, en vez de desafiar tal prejuicio, algunos investigadores intentaron ir por el camino más simple de probar la existencia de escritura y así elevar el carácter civilizatorio de las sociedades andinas prehispánicas.

Parte de dicha historia de búsqueda de escritura prehispánica fue desarrollada por el arqueólogo inglés Ricardo Latcham, director del Museo Nacional de Historia Natural de Chile entre 1928 a 1943. De profesión ingeniero y de autoformación en arqueología, Latcham fue uno de los principales investigadores sobre las culturas prehispánicas de Chile, sistematizando la prehistoria del país y contribuyendo sobre todo al estudio del pasado atacameño y la definición de la cultura Diaguita. Su trabajo de investigación se basaba tanto en el trabajo en terreno de excavación como en el estudio de colecciones arqueológicas. En esta línea, una colección de alfarería presuntamente prehispánica que procedería de Ica, Perú, convencería a Latcham de que su decoración podría ser ideográfica, dando claves importantes sobre el desarrollo de la escritura prehispánica. Tal motivación lo llevó a adquirir dicha colección a un alto costo, dando cuenta de sus interpretaciones a través de una serie de publicaciones científicas.

Las principales fuentes de información para el presente estudio provienen de artículos publicados por Latcham, además de los libros de inventario de antropología y del Archivo Histórico Administrativo del Museo Nacional de Historia Natural (AHA). Este último contiene importante información de correspondencia entre Latcham y otros investigadores, en la que se pueden apreciar las discusiones y debates internos sobre su interpretación arqueológica.

\section{UNA COLECCIÓN DE ALFARERÍA CON "GLIFOS ESCRITURALES"}

La historia de la adquisición de la colección mencionada comienza en el año 1929, cuando se acercan a Ricardo Latcham los señores Jorge Eckart y Rafael Tononi, anticuarios de Santiago, con el fin de ofrecerle una colección de piezas de alfarería prehispánica. Dicha colección despierta gran interés en él, porque eran piezas únicas en su estilo formal y con una decoración que podría indicar la presencia de signos escriturales (figs. 1 y 2). 
Es así como un 20 de agosto de 1929, Latcham acordó con Eckart y Tononi el canje de 40 piezas de alfarería definidas como de la cultura "Proto-Nazca" (AHA 32007). La definición de Proto-Nazca había sido propuesta por el arqueólogo Max Uhle (Bischof 1998) y agruparía principalmente las manifestaciones culturales del Período Intermedio Temprano caracterizado en la costa sur del Perú por la transición entre la cultura Paracas y Nazca. El valor de dichas piezas de alfarería fue estimado en $\$ 13.000$, una fortuna para la época, considerando que el sueldo promedio del personal del Museo era de $\$ 566$ pesos mensuales (AHA 32-002, junio de 1929). Dada la falta de dinero en efectivo para tal compra, la crisis económica mundial y el sumo interés de Latcham por adquirirlas y dar con un gran descubrimiento, decidió este obtenerlas por medio de un canje con otros artefactos que formaban parte de la colección del Museo Nacional. Dichos artefactos corresponden principalmente a una gran cantidad de piezas de platería mapuche, además de armas antiguas con incrustaciones de marfil y oro. El listado de objetos intercambiados fue el siguiente:

un sable con guarniciones doradas y pedrería, un sable turco con incrustaciones de oro, una pistola con incrustaciones de marfil, una pistola con incrustaciones de oro, 145 cucharitas de memento o recuerdo, un apero completo para caballo con adornos de plata, 26 trapelacuchas de plata araucanas, 6 topus araucanos de plata, 2 punzones de plata, 7 trapelacuchas de caño de plata, 2 trariloncos con adornos de monedas de plata, 2 mitrohues con adornos de plata, una cucharita boliviana de plata, un crucifijo de plata, 2 mates de plata, 3 bombillas de plata, una tacita de plata, 2 estribos de plata, un par de estribos de plata, 4 pares de espuelas de plata, 2 pares de espuelas enchapadas, una espuela enchapada, un par de espuelas enchapadas, dos vitrinas, tres espejos antiguos en muy mal estado, una silla antigua en muy mal estado, un pedazo de reja de ventana de cobre, un jarro de cobre, cabeza de alabarda (AHA 32-007, 20 de agosto de 1929: 2).

Por lo que se describe en los artefactos del canje, hay un claro interés hacía la platería, tanto mapuche como colonial. Lo anterior, más las armas y muebles antiguos, de seguro serían objetos que podrían alcanzar un alto valor de reventa en el mercado, y por ende, eran de gran interés para los anticuarios. Eckart y Tononi tenían un local de antigüedades en calle Huérfanos 1170, en Santiago centro, y estaban dedicados a la compra de "joyas, objetos, plata, marfiles, cuadros, muebles, santos de madera, casullas, abanicos, porcelanas, mantones, manila, etc." (La Nación, 13 de setiembre de 1929: 31). Ellos ya tenían experiencia en el ofrecimiento de antigüedades a museos, como lo demuestra la venta en 1918 de una figura de San Antonio de Padua de época colonial al Museo Histórico Nacional (Martínez 2011). La información de prensa denota que la especialidad de estos anticuarios era principalmente las antigüedades del período colonial, más que las piezas de origen prehispánico.

Es importante destacar que para dicha época no existía una política de canje ni compra de colecciones en los museos del país, quedando en gran medida a criterio del director de cada institución los parámetros para la disposición y manejo de las colecciones. En el Museo Nacional de Historia Natural, por ejemplo, los canjes al extranjero de colecciones naturales y antropológicas fueron frecuentes desde sus inicios, lo que permitió visibilizar las colecciones nacionales de modo internacional y cosmopolitanizar la muestra de exhibición. Sin embargo, no existía un criterio definido sobre qué se podía adquirir, ni había un financiamiento estable, por lo cual lo que ingresaba y lo que salía en cuanto a colecciones dependía de las gestiones de cada investigador de la institución y de la dirección del Museo.

Poco tiempo después de haber adquirido aquellas 40 piezas de alfarería, Latcham publicaría en el Boletín del Museo Nacional de Historia Natural un artículo titulado "Figuras que parecen geroglifos, en la alfarería Proto-Nazca”. Más allá de describir las piezas de alfarería, el objetivo principal de Latcham era dar cuenta pública de su presunto descubrimiento de un sistema de escritura prehispánico, lo cual, de ser correcto, sería un acontecimiento de relevancia mundial para la disciplina. Lo que motiva el artículo de Latcham,

\footnotetext{
es el hecho de presentarse en algunas de las piezas, una serie de signos dibujados, que las distingue de todas las que hasta ahora se han descrito o figurado en las diversas publicaciones, o en los numerosos ejemplares que hemos podido examinar personalmente. Dichos signos son, al parecer, ideográficos y forman verdaderas inscripciones (Latcham 1929: 93).
}

Latcham se refiere a otros posibles casos de escritura precolombina con grabados en alfarería a partir de un artículo de Vélez López y de escritura en textiles publicado por Franz Heger, ambos presentados en el Congreso Internacional de Americanistas de 1924. Según su opinión, las figuras registradas en esta colección "Proto-Nazca":

Son de estilo más primitivo y parecen derivarse, en parte, de una pictografía zoológica bastante estilizada, figurando en 

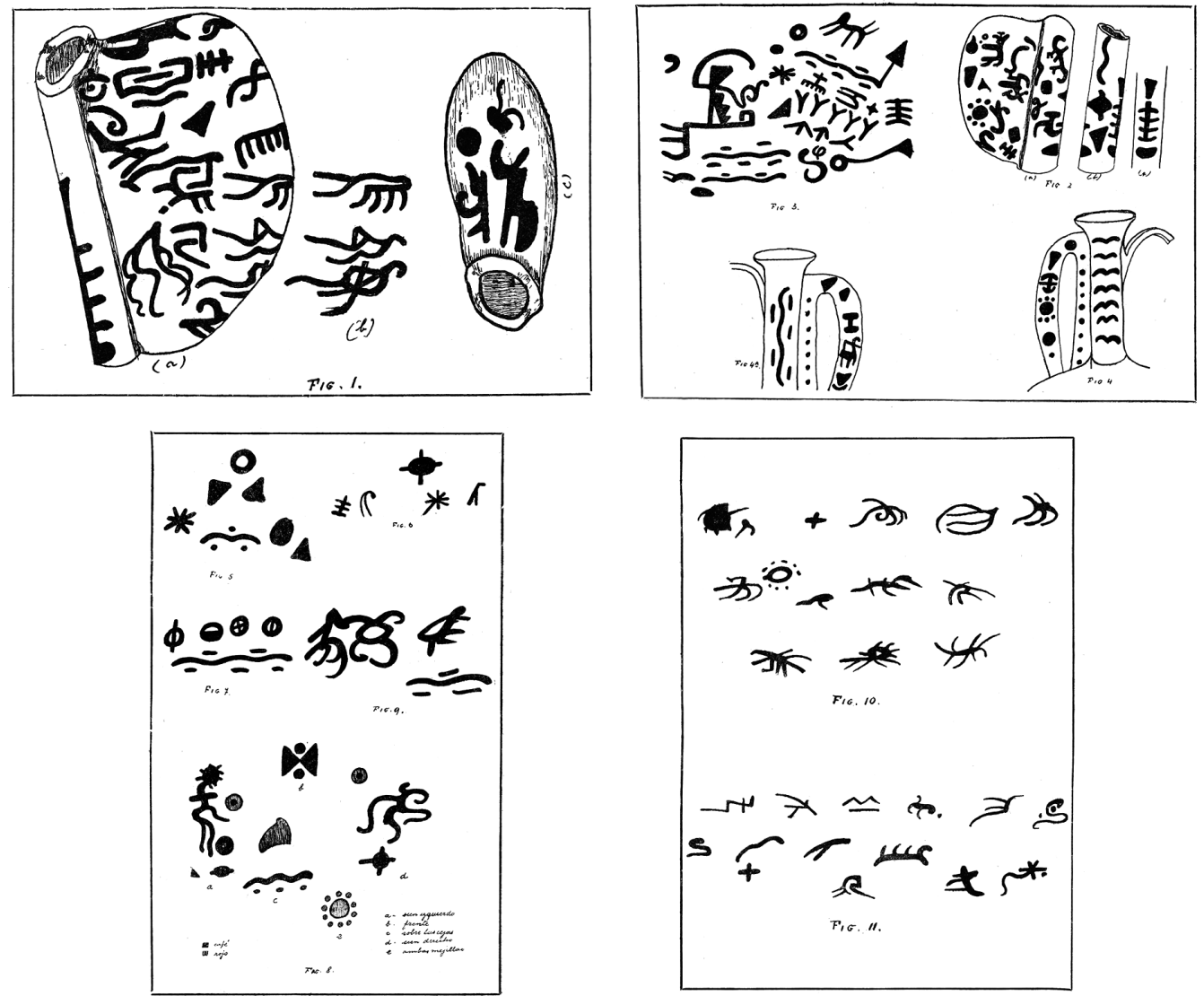

Figura 1. Láminas de los glifos identificados por Latcham en la colección "Proto-Nazca" adquirida por el Museo. Figure 1. Sheets of the glyphs identified by Latcham in the "Proto-Nazca" collection acquired by the Museum.

primer término la línea ondulada, con un extremo ligeramente abultado, que hace pensar en la figura de una serpiente. Luego hay algunos que aparentan ser figuras estilizadas de cuadrúpedos y aun de seres humanos. Otros son más bien geométricos-círculos, cuadrados, triángulos, etc., con o sin otras figuras anexas (Latcham 1929: 94).

El artículo solo tiene tres páginas de texto más otras de fotografías e ilustraciones de los "glifos" detectados por Latcham. Si bien, se da un detalle muy general de la colección expuesta, Latcham promete en el artículo dejar para otra ocasión un estudio más prolijo de dicha alfarería. La rapidez en publicar esta investigación, sin un mayor análisis de detalle, responde posiblemente al gran entusiasmo generado por tan sensacional descubrimiento, adelantándose a cualquier posible competidor.
Cuando el artículo salió a la luz pública, el mismo Latcham se preocupó de promover su relevancia y buscar la validación de otros expertos dedicados a la arqueología andina. De esta forma, el 30 de junio de 1930 escribiría una carta al destacado arqueólogo peruano Julio Tello, director del Museo de Arqueología, Antropología e Historia del Perú. Junto con la carta, Latcham envía un dosier de sus publicaciones, pero se detiene en dar a conocer su último artículo sobre los "glifos", con el fin de expandir el impacto de su hallazgo y conseguir validación académica, en una época en que no era común la revisión de pares en publicaciones científicas. En la carta se detiene en la descripción un poco más detallada de las vasijas y promete que en el siguiente número del Boletín del Museo hará una descripción 
mejor de las mismas. Latcham menciona además que las piezas fueron examinadas por el arqueólogo norteamericano Samuel Lothrop, quien en esos días estaba en Chile realizando investigaciones arqueológicas, y para su juicio serían originales (AHA 34-011: 6-7). De hecho, Latcham le entregaría una de estas vasijas a Lothrop, la cual fue llevada al National Museum of the American Indian, que estaba en Nueva York (Latcham 1933: 55), dando así un temerario paso hacia la búsqueda de una validación internacional a su teoría.

Julio Tello respondió a la carta de Ricardo Latcham con fecha del 14 de julio de 1930, manifestando su sorpresa e interés por aquella publicación. Por una parte, Tello le expresa que las imágenes publicadas de las piezas corresponderían de modo general a la cultura Nazca, la cual derivaría de una "arcaica cultura Andina", pero le hace notar que algunos de los motivos de la decoración y los signos "jeroglíficos" podrían ser falsificados:

A este respecto le diré que dichos signos son muy semejantes, sino idénticos, a los que ornamentan una clase de alfarería procedente según se dice de Tiwanako o de Bolivia, que desde algún tiempo ha aparecido en el mercado, y que Posnansky la considera como falsificada, basándose, entiendo, sólo en testimonios no bien fundamentados. Yo creo que la colección por usted adquirida va a resolver este problema. Si como usted cree los objetos no son falsificados, deben corresponder probablemente a la cultura Andina, tal vez a una modalidad de la alfarería Andina constatada en el valle de Nazca (AHA 54-101 14 de julio de 1930:2).

De modo sutil, Julio Tello introducía una duda sobre el carácter de autenticidad de las piezas publicadas por Latcham y, más aún, cuestiona la fuente sobre la cual él se basaba para hablar de posibles antecedentes de escritura en los Andes, diciendo: "El trabajo de Vélez López ¿Existió la escritura en los Yungas? se basa en objetos falsificados" (AHA 54-101, 14 de julio de 1930:2). Para zanjar el debate de modo empírico, Tello ofrece a Latcham la posibilidad de revisar personalmente la colección con mayor detalle, ya sea a través de fotografías, o bien enviándole un ejemplar de alfarería a través del consulado chileno, con el compromiso de su devolución por correo.

Posteriormente, con fecha 15 de noviembre, Latcham redacta una carta de respuesta a Tello, excusándose por la demora debida a los trabajos de remodelación de la fachada del edificio del Museo. Él afirma que no posee datos suficientes sobre el origen de las piezas, pero que fueron encontradas en Huamani, valle de Ica, por un tal José Fuste de Lima. A su muerte, la colección la habría heredado una hermana que la vendió a un comerciante de La Paz, Bolivia, quien a su vez la vendió en Santiago de Chile (AHA 34-011, 15 de noviembre de 1930: 21). Con respecto al tema de la decoración de apariencia Tiwanaku en las vasijas descritas, Latcham se defiende invirtiendo el argumento de Tello: "En cuanto a lo que Ud. me dice de la cultura arcaica Andina, quizá tenga razón y estas piezas parecen corroborarlo; pues en algunas se encuentran las cabezas de pumas y cóndores típicos de Tiahuanaco, como, a la vez, figuras escalonadas y otras de monstruos que recuerdan algunos de los reproducidos por Posnansky" (AHA 34-011, 15 de noviembre de 1930: 22). De la misma forma, lo que Tello sutilmente expresa sobre la posibilidad de que cierta alfarería con estilo Tiwanaku sea falsificada, Latcham contesta asumiendo lo contrario:

\footnotetext{
Respecto de lo que me dice acerca de la alfarería tiahuanaqueña con inscripciones, tenemos aquí en el museo un vaso con inscripciones, de esa procedencia. Yo estaba dispuesto a considerarlo como apócrifo o falsificado, a pesar de ser su técnica y ornamentación muy semejantes por no decir idénticos a las de las piezas auténticas; pero en vista de lo que Ud. me dice, estimo que será más prudente reservar mi opinión (AHA 34-011, 15 de noviembre de 1930: 23).
}

Latcham se compromete a enviar a Tello una de las vasijas de la colección por medio de la embajada del Perú, con el compromiso de ser devuelta. Lamentablemente, no tenemos información de si esto finalmente fue llevado a cabo efectivamente o si Tello envío alguna nueva carta de respuesta a Latcham.

A partir de 1929 comienza una serie de transformaciones estructurales en el edificio del Museo que lo mantuvieron cerrado por algunos años, debido a lo cual el boletín de la institución no se publicó entre 1930 y 1935. Por ello, los nuevos artículos de Latcham sobre las vasijas de Ica aparecen en la Revista Chilena de Historia Natural durante este período. En 1933 publicaría un artículo en el que aporta nuevos detalles descriptivos sobre la colección cerámica con presencia de glifos, mencionando de modo explícito su proveniencia desde Huamani en Ica. Retomando lo mencionado en su correspondencia con Tello, Latcham reconoce la presencia de elementos decorativos Tiwanaku en esta alfarería "Proto-Nazca", pero lo atribuye a la "cultura Andina", como ente primigenio del cual derivaría el resto de las manifestaciones culturales del Perú, incluso previo a Chavín de Huantar, considerada en esa época como 


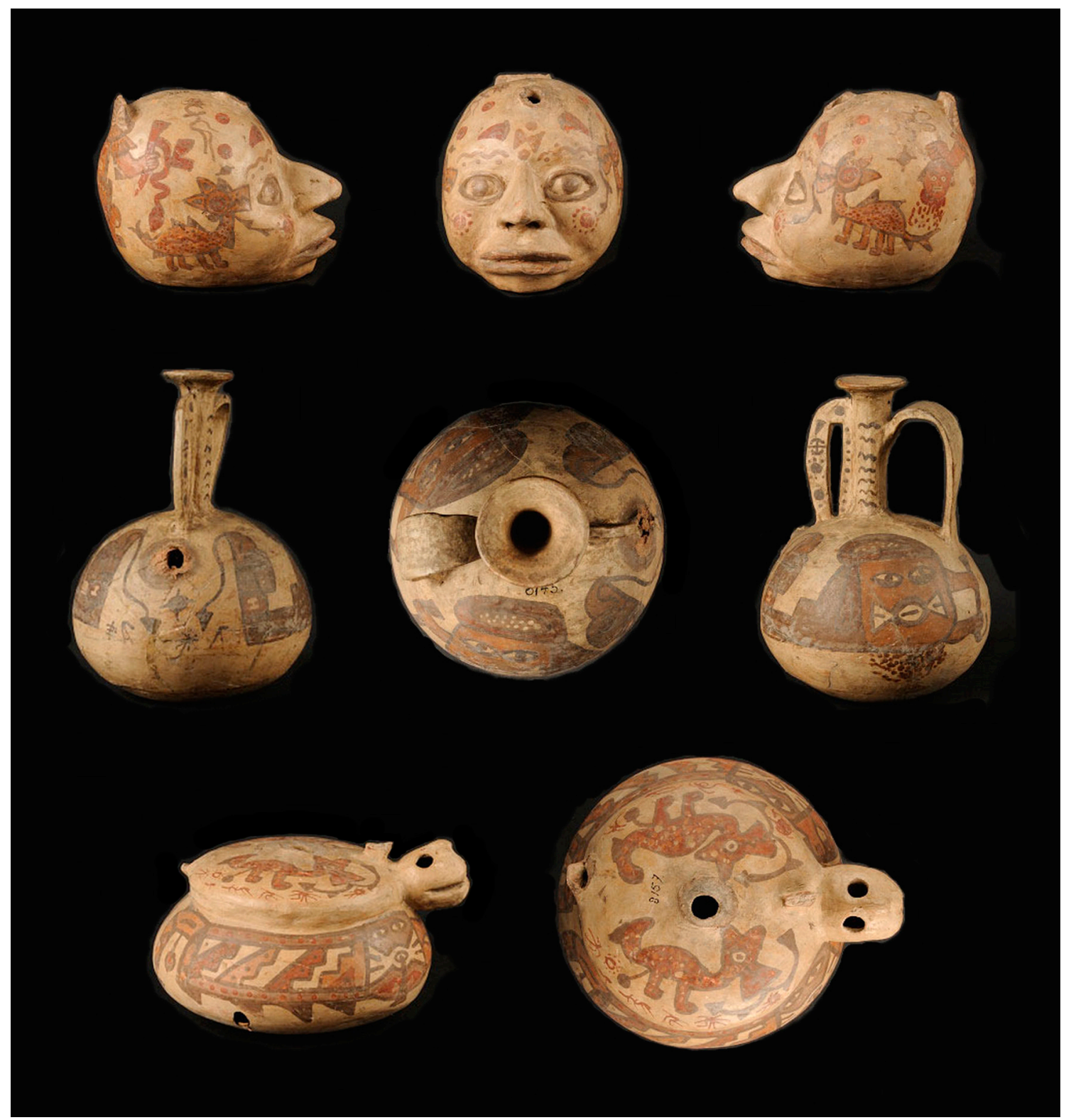

Figura 2. Vista de algunas de las vasijas de la colección "Proto-Nazca" adquirida por Latcham. Figure 2. View of some of the vessels of the "Proto-Nazca" collection acquired by Latcham.

la primera "civilización" sudamericana. De este modo, Latcham asume un marco interpretativo hiperdifusionista y a la vez evolucionista para explicar similitudes culturales y así validar su interpretación. En el artículo se señala que todas las piezas tienen una manufactura y color de fondo uniforme, representando figuras míticas a las cuales se les atribuye sexo femenino. Sobre los "glifos", plantea que hay "una serie de signos dibujados en sepia que los distingue de todos los que ahora se han descrito o reproducido en diversas publicaciones, o de los que conocemos personalmente. Dichos signos son, al parecer, ideográficos y forman verdaderas inscripciones" (Latcham 1933: 50).

En 1934, Latcham entrega una continuación de la descripción de las vasijas en la misma revista, agregando que la alfarería de Ica es más realista y primitiva que la 
de Nazca, "pero con los motivos fundamentales idénticos en las dos" (Latcham 1934: 59). Además, describe nuevos motivos decorativos de la alfarería de Ica, dando cuenta de que la mayor parte de los personajes fantásticos serían de sexo femenino y representarían "figuras humanas estilizadas, envueltas en grandes capas ceremoniales y totémicas, de pieles de animales, aves, etc., con la cara cubierta de una máscara. Esto las hace parecer monstruos, pero en todo caso las extremidades superiores e inferiores son humanas" (Latcham 1934: 59).

En un tercer y último artículo publicado sobre esta colección en 1935, Latcham ahonda en su especulación. Desarrollando su interpretación sobre el sexo de los personajes representados, relaciona esto con posibles aspectos de organización social en términos de estructura de parentesco matriarcal primigenia, basándose en las antiguas ideas de Johann Bachofen (1967 [1861]), reproducidas luego por el evolucionista social Henry Morgan (1985 [1877]): “Hace sospechar que el pueblo que producía esta alfarería se encontrase en un estado matriarcal, o a lo menos que conociese la filiación materna, universal en toda la región andina en tiempo de la conquista española" (Latcham 1935: 9). Asimismo, y basado en una escena de la decoración, argumenta una fantástica guerra primordial entre ambos sexos:

Nos parece que este grupo representa la lucha entre dos tribus o grupos totémicos -los leones y los jaguares- en que este último sale victorioso. A juzgar por el sexo de las dos figuras, los pumas estarían en estado patriarcal y los jaguares en estado matriarcal. Puede ser también que la lucha represente la competencia entre los hombres y las mujeres para la supremacía social. Debe tornarse en cuenta que en tiempo de la conquista española la mayoría de las tribus andinas dedicadas a la agricultura todavía reconocían la filiación materna, vestigios del matriarcado y solamente entre los pueblos nómades de cazadores regía la filiación paterna (Latcham 1935: 9).

En una línea paralela a la anterior, Latcham también profundiza en las relaciones culturales de este estilo cerámico, sobre todo en función de su similitud con otras sociedades andinas:

Las cabezas de cóndor y de puma que aparecen en la decoración de algunos de los vasos, en el estilo que se hizo clásico en el arte de Tiahuanaco, nos hacen sospechar que las influencias de la cultura representada por la cerámica de Ica, se extendieron hasta la Sierra y altas planicies peruano-bolivianas, proporcionando motivos artísticos a esa civilización. Las semejanzas son tan precisas que no pueden existir dudas respecto de la intimidad de estas relaciones (Latcham 1935:10).
En otra descripción, Latcham menciona: "La cabeza del cóndor está dibujada exactamente de la misma manera como en el arte clásico de Tiahuanaco. Del mismo modo en que las dos caras humanas se dan frente en un lado del vaso, las cabezas de cóndor se dan frente en el otro. Entre ellas y debajo del pico roto del vaso, se encuentra una serie de cinco jeroglíficos" (Latcham 1935: 10). En vez de cuestionar la autenticidad de la similitud, Latcham da cada vez un paso más allá en sus interpretaciones y avanza en la idea de que estas vasijas representan una cultura ancestral originaria de gran parte de las manifestaciones culturales futuras en los Andes, llegando incluso hasta el altiplano.

Luego del artículo de 1935, no hay nuevas publicaciones al respecto de esta colección de alfarería, llegando a describir en detalle unas 12 de las 40 vasijas originalmente adquiridas. Latcham no cuestionó nunca la autenticidad de sus fuentes empíricas y en sus distintas publicaciones generó una interpretación ad-hoc y muy poco crítica para explicar su origen y decoración. Sin embargo, no se aventuró en el desciframiento del contenido de los glifos que describió, aunque sí realizó aventuradas interpretaciones de sus escenas decorativas, como hemos visto en el ejemplo de la batalla entre hombres leones y mujeres jaguares. Durante su vida, e incluso luego de su muerte, estos artículos no tuvieron mayor repercusión en el contexto nacional por tratarse de una colección extranjera, ni tampoco fueron mayormente citados o discutidos fuera del país. Asimismo, nadie expresó de modo público dudas acerca de la autenticidad de la colección o de las interpretaciones generadas por Latcham.

La autenticidad de las piezas de alfarería con glifos se pondría en duda en la década de 1950, aunque solo a nivel interno en el Museo. La arqueóloga peruana Rebeca Carrión, directora del Museo Nacional de Antropología, Arqueología e Historia del Perú, en Lima, y sucesora de Julio Tello, tuvo una relación profesional y de amistad con la arqueóloga del Museo Nacional de Historia Natural, Grete Mostny, visitando Chile a mediados de 1954 (AHA 35-296). Ellas llevaban discutiendo desde hace un tiempo la posibilidad de establecer canjes interinstitucionales de artefactos arqueológicos, además del interés de visitar la colección de arqueología peruana presente en Chile. En su viaje a Chile, Carrión pudo ver la colección adquirida por Latcham, desacreditando finalmente su origen bajo su opinión experta. Esto quedó consignado con una anotación de observación 
en el registro del libro de inventario del Museo asociado a tales piezas: "Toda esta colección es falsificada según Rebeca Carrión" (Inventario Antropología MNHN, Libro III: 78). Desafortunadamente, dicha noticia no trascendió fuera del Museo, tampoco hubo comentario académico que corrigiese o criticase la publicación de Latcham.

$\mathrm{Al}$ analizar las piezas identificables de dicha alfarería en la colección del Museo Nacional de Historia Natural, podemos ver que, en efecto, presentan características morfológicas muy poco usuales para la alfarería Nazca o Paracas. En la apreciación contemporánea, su carácter de falsificación es evidente y se demuestra no solo por sus extraños signos o "glifos", sino por la morfología de las asas, el alargado y delgado cuello, la representación de una vasija con forma de cabeza humana que nada concuerda con otras de la época y la región, además de la presencia de otra vasija zoomorfa de muy dudoso estilo. Más allá de la morfología, su decoración muestra personajes humanos y otros con forma de animales marinos antropomorfos con cabezas trofeo que concuerdan con la decoración Paracas y Nazca, pero mezclados con felinos de atributos de la cultura Tiwanaku que ninguna relación tienen con esta alfarería. Finalmente, en la vasija con forma de cabeza humana se observan figuras de animales que resemblan una especie de "dinosaurio" con el lomo arqueado y una cresta en zigzag, motivo que no existe en ninguna otra vasija prehispánica conocida.

Estas costosas vasijas que indujeron a Latcham al error, fueron exhibidas por un tiempo indeterminado, posiblemente hasta la década de 1950 (fig. 3), y luego cayeron en el olvido, siendo conservadas en el depósito de la institución, donde permanecen hasta hoy. Desafortunadamente, no tenemos registros de archivo sobre la historia de estos artefactos en la exhibición, lo cual limita el saber cuándo fueron sacados de la vista pública. Sin embargo, una historia paralela que involucra a anticuarios y el debate por el desciframiento de una antigua escritura se vería reflejado posteriormente en una nueva obra de Ricardo Latcham, pero esta vez con nuevos referentes: los piratas de la bahía de Guayacán.

\section{PIRATAS, TESOROS Y FÁBULAS}

En este acápite presentamos una faceta distinta de la obra de Latcham que, hasta cierto punto, reafirma su obsesión por el tema de escrituras indescifrables y anticuarios, aunque en esta ocasión cambia las coordenadas

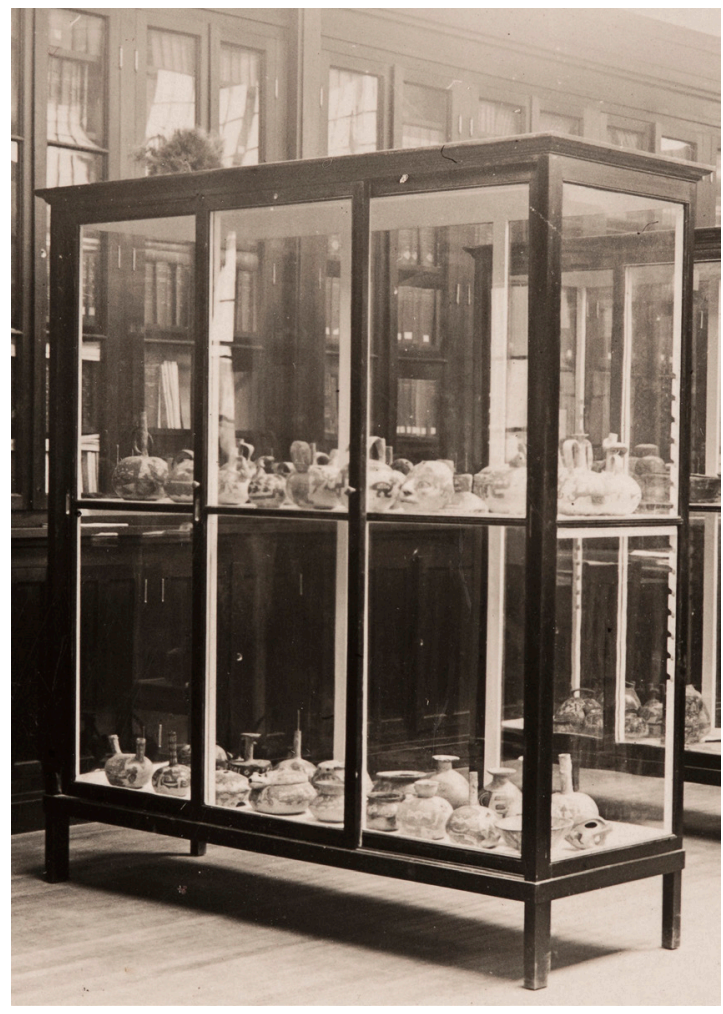

Figura 3. Vitrina del Museo Nacional de Historia Natural donde se exhibieron las vasijas de la colección "Proto-Nazca" adquirida por Latcham. Figure 3. Display cabinet at the National Museum of Natural History where the "Proto-Nazca" vessel collection acquired by Latcham was exhibited.

espacio-temporales y le agrega una historia de cazadores de tesoros y piratas. Nuestro argumento es que Latcham, de modo consciente o no, expresa en esta obra parte de su frustración por el poco impacto de su "descubrimiento" previo, el cual posiblemente también sembró dudas en sí mismo sobre su autenticidad. La súbita interrupción de sus publicaciones sobre la colección de alfarería de Ica en el año 1935 podría ser un indicio de aquello, aunque él nunca lo comunicó públicamente.

En 1935, Latcham lanza un nuevo libro. Su título es El tesoro de los piratas de Guayacán. Relación verídica, en el que narra una historia supuestamente real de un tesoro enterrado. El relato presenta interesantes similitudes con la historia por la cual él llega a realizar su interpretación de glifos escriturales en alfarería prehispánica. Escrito en un estilo novelístico y sin explicitar su carácter de ficción, el libro se plantea como una narración factual e histórica. Su forma de escritura se acerca a un género literario de aventuras muy popular entre las décadas 
de los 30 y los 50, donde las narraciones de historias de tesoros ocultos, aventuras en parajes inhóspitos y misterios sin resolver, captaban la atención de un gran número de lectores. En el mundo anglosajón, el escritor Harold T. Wilkins (1891-1960) fue un referente de este género literario en la época, cosechando grandes éxitos con obras como Hunting hidden treasures (1929), Modern buried treasure hunters (1934), Panorama of pirate treasure (1940), Mysteries of ancient South America (1946), entre otras. Además, fue uno de los primeros autores en publicar libros sobre naves alienígenas con Flying saucers on the attack, en 1954. Lo relevante es que Wilkins cita a Latcham y su investigación del tesoro de Guayacán en Modern buried treasure hunters, un año antes de la publicación chilena, como si se tratase de hallazgos reales. Esta cita comprueba que ambos autores establecieron algún tipo de relación, la cual seguramente influenció el estilo de narrativa que Latcham desarrolla en su obra. El libro El tesoro de los piratas de Guayacán (1935) sigue dicha línea narrativa.

En cuanto a su estructura, la obra se divide en cuatro partes: la primera, dedicada al descubrimiento de documentos escriturales; la segunda, a las investigaciones del autor; la tercera, a la documentación; y por último, el apéndice, acerca de Francisco Drake en el Pacífico. La novela incluye fotografías de los lugares donde suceden los hechos, como las cavernas, las ruinas de fortaleza, la Playa Blanca y la Punta de Cicop, entre otras. También hay dibujos de los glifos encontrados, cuyo parecido con los dibujos de la colección adquirida en el Museo por Latcham en 1929 es bastante asombroso (fig. 4). Todos estos elementos, tanto las fotografías como los dibujos, pretenden darle cierto aspecto de verosimilitud histórica, como si se tratara de un libro de investigación científica.

En el libro, Latcham es la voz del narrador y cuenta que un día de septiembre de 1930 lo llamó a su despacho el director general de Bibliotecas, Archivos y Museos, para comentar la visita del Dr. Cohe, un lingüista y anticuario aficionado, quien le había referido un descubrimiento de documentos antiguos, entre estos, una plancha de cobre cubierta de extrañas inscripciones. Estos habían sido encontrados en la bahía de Guayacán por un campesino local llamado Manuel Castro, ${ }^{1}$ quien excavó en un lugar donde en 1926 había llegado un buque de vela en busca de un tesoro pirata del siglo xviI. Desde aquel barco habrían desembarcado 27 extranjeros que incluían ingleses, franceses, alemanes, holandeses, daneses, un estadounidense, un portugués y un español. Manuel
Castro y su hermana Rita hipotecaron lo poco que tenían para hacer las excavaciones y descubrieron una plancha de cobre que, por ambos lados, estaba cubierta de una serie de signos que parecían letras y algunos dibujos, entre los cuales se distinguía una carabela, un cañón y una rosa.

Manuel y Rita no pudieron descifrar la escritura y por ello recurrieron a un señor extranjero con quien Castro tuvo algunos negocios, a quien se le llama "Senor X”. Ellos forman una sociedad, mediante la cual el Señor X se encargaría de hacer traducir la plancha por un traductor residente en Buenos Aires, muy versado en lenguas modernas. Manuel Castro habría continuado excavando y hallaría una vasija con pergaminos que poseían una escritura similar a las planchas de cobre, una virgen de oro, navajas españolas, una estrella de plomo de seis puntas y una moneda del tiempo de Pericles. Cuando el resultado de la traducción llegó, se habría confirmado que la escritura correspondía a lenguas arcaicas orientales, y se incluía una afirmación firmada por el pirata Subatol Deul del año 1640, señalando la existencia de un tesoro. En las supuestas traducciones se confirmaría que Deul era un pirata hebreo y habría ocupado en gran parte este alfabeto, mientras que otros signos provendrían del griego arcaico. Sin embargo, ante la clara traducción letra por letra del alfabeto hebreo al español, Latcham afirma: "Aun cuando los piratas eran orientales y no había entre ellos ningún español, han empleado el castellano para hacer su documentación... la razón de esto no hemos podido explicárnosla" (Latcham 1935: 96). En los documentos se narra la llegada de los piratas Subatol Deul (hebreo) y Ruhual Dayo (normando o flamenco) entre 1599-1600. Deul y Dayo se encontraron con el barco de Enrique Drake, un supuesto hijo de Francis Drake, y junto con este conformaron la Hermandad de la Bandera Negra. Todo esto confirmaría, según el autor, que Deul depositó su tesoro en Guayacán y deja abierta la posibilidad de que otros puedan desentrañar este misterio, como expresa el narrador: "No puede pensarse en una tentativa de estafa, pues las dos personas interesadas, en cuya posesión estaban los documentos, lejos de tratar de negociar o explotar estos, los guardaban en el mayor secreto y recelo..." (Latcham 1935: 160).

Cuando Latcham se involucra en la investigación gracias a una comisión de servicio, habría viajado al lugar del descubrimiento para revisar en detalle el asunto. Latcham describe su viaje a Coquimbo en octubre 


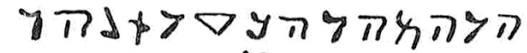

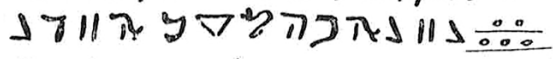

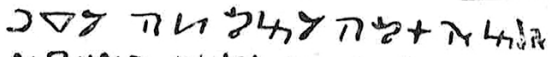

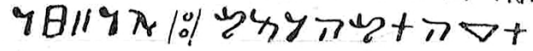

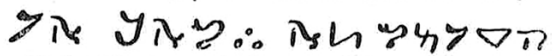
$*+\pi \nabla+y \wedge$ บ

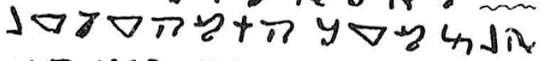

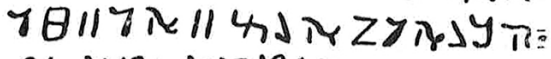
-24

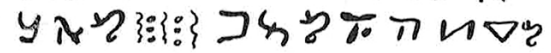

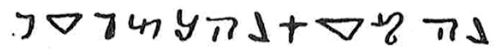
$\pi 2+\nabla+2$ थ $+\nabla \infty$

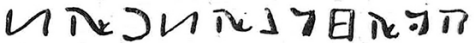

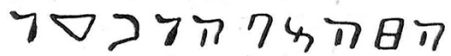

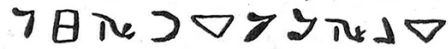

$$
\begin{aligned}
& \text { Уオ Уता }
\end{aligned}
$$

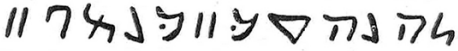

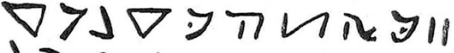

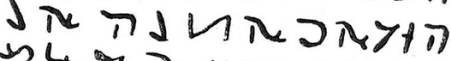

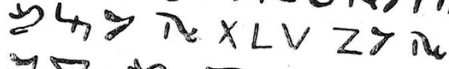

$$
\begin{aligned}
& \Rightarrow \nabla 0 D . T
\end{aligned}
$$

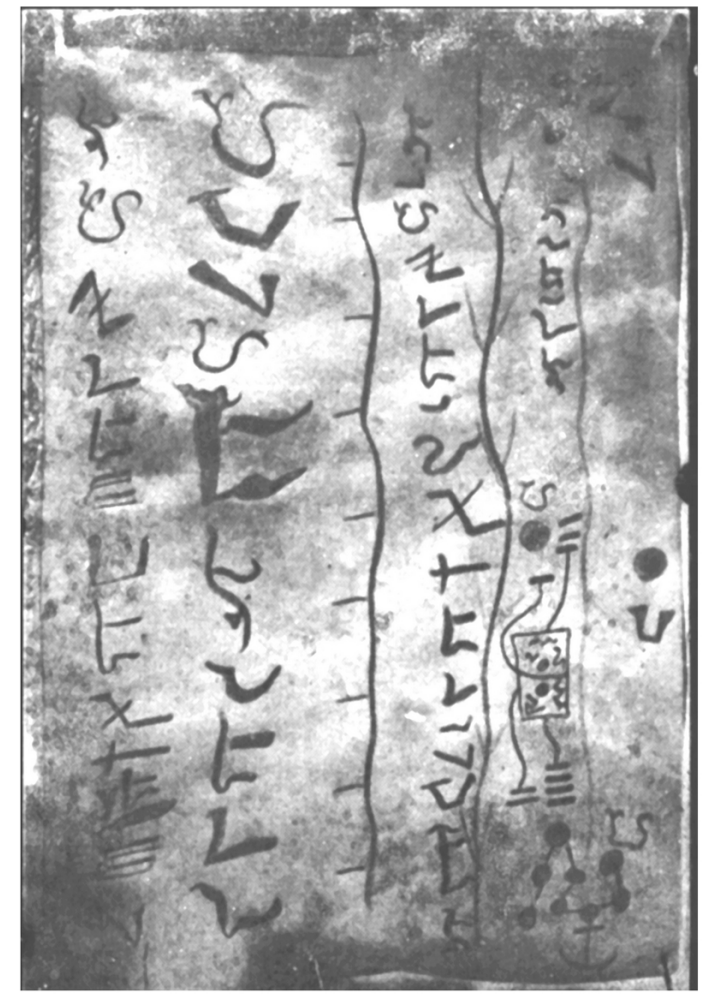

Figura 4. Vista de algunos de los supuestos documentos transcritos y original, publicados por Latcham en El tesoro de los piratas de Guayacán (Latcham 1935). Figure 4. View of some of the transcribed and original alleged documents, published by Latcham in El tesoro de los piratas de Guayacán (Latcham 1935).

de 1930; allí conocería a Castro y visitaría los lugares donde se realizaron las excavaciones. Luego de haber revisado las copias de los pergaminos y trabajado con un teodolito para referenciar los puntos geográficos del supuesto lugar subterráneo del tesoro y una mina de oro explotada por los piratas, él mismo daría instrucciones a Castro sobre los lugares para seguir excavando. Por razones de fuerza mayor Latcham se vio obligado a regresar a Santiago y siguió en comunicación con Castro por correspondencia. A partir de eso, supo que Castro habría hallado nuevos documentos enterrados en la zona designada por Latcham, lo que hacía dicha zona más probable para la presencia del tesoro. Finalmente,
Castro desapareció misteriosamente y Latcham decidió dar a conocer la historia, considerando que más allá del tesoro, la narración tendría un gran valor histórico por los documentos encontrados. Sobre el tesoro, concluye diciendo: "Y ahora, lectores, dejamos a vuestro ingenio el deshilvanar la trama de este misterio, deseándoos mejor suerte que la que nos ha tocado en nuestra investigación del asunto" (Latcham 1935: 160).

El libro de Latcham y su dudosa documentación, la cual no cuestiona a pesar de nunca haberla visto en persona, establece un quiebre con su obra previa dedicada principalmente a la arqueología con evidencia empírica. Esta narrativa histórica no sería la primera 
obra de tal tipo de Latcham, ya que en el año 1929 publicó La leyenda de los Césares, en la que da cuenta del origen de este relato fabuloso, pero de forma mucho más crítica respecto de las fuentes, dando siempre a entender que era una leyenda. Se trata de la historia de una ciudad mítica "habitada por un pueblo que tenía grandes riquezas de oro, plata y piedras preciosas" (Latcham 1929: 193). Desde el comienzo establece que hay muy pocos elementos de veracidad en la historia, basados en relatos de expediciones españolas que habían sido interpretados de modo acrítico por investigadores, como Benjamín Vicuña Mackenna y Ciro Bayo, quienes escribieron ensayos literarios al respecto. Por ende, la historia de los piratas de Guayacán contrasta aún más con su línea de investigación precedente, específicamente en lo referente a la crítica de fuentes.

De acuerdo con la información del Archivo Histórico Administrativo del Museo Nacional de Historia Natural, no existe ninguna documentación que acredite su comisión de servicio a Coquimbo y Guayacán en las fechas señaladas en el libro. Solo hay registro de un viaje en julio de 1929 a dicha ciudad, con el fin de realizar la compra de fósiles al señor Ramón Escutti Orrego (AHA 32-011). A la vez, es relevante destacar que entre 1929 y 1932, Latcham se vio afectado emocionalmente debido a un problema de bienes relacionado con el arriendo del fundo Bellavista, de su propiedad, ubicado en Monte Patria, al interior de Ovalle. El antiguo arrendatario, Benjamín Barrios, luego de once años dejó de pagar el arriendo a causa de la crisis económica mundial, siendo reemplazado por Enrique Varela. Este último arrendatario, le pedía prórrogas de pago y rebajas, lo cual tenía en una situación angustiosa a Latcham, quien le respondía que su petición era "como quien solicita revólver en mano... como había contado con ese dinero para cancelar negocios y compromisos pendientes, no me veo en el caso de hacer nuevas rebajas en este momento" (AHA 102-018, 11 de junio de 1931). Latcham se dedicó a buscar nuevos arrendatarios y finalmente, en noviembre de 1931, quien aceptó las condiciones fue el señor Patricio Castro. Esta persona de apellido Castro es la única de la cual tenemos registro de correspondencia con Latcham. Podríamos deducir que los problemas que afectaban a Latcham influyeron, de cierta forma, en la construcción de las historias narradas en su libro. Sin embargo, carecemos del testimonio del autor para determinar el peso de sus experiencias personales en este giro hacia la literatura.
El libro de los piratas de Guayacán fue uno de los más exitosos de Ricardo Latcham, contando con tres ediciones a la fecha: 1935, 1976 y 2018 . El uso de esta obra se ha extendido como texto de validez histórica a nivel mundial, nutriendo narrativas de libros de piratas como el de Milton Meltzer (2001), entre muchos otros. Del mismo modo, algunos de sus personajes, como el pirata hebreo Subatol Deul, figuran en relatos de diversas páginas de instituciones judías que abordan la influencia de los judíos en América, ${ }^{2}$ y han aparecido en novelas, como la famosa Aventuras de Edmund Ziller, del escritor argentino Pedro Orgambide (1977), además de varios libros de difusión y esoterismo. ${ }^{3}$ Como podemos ver, la influencia y alcance del libro de Latcham se ha extendido hasta la actualidad, pero sin cuestionamientos ni dudas sobre sus fundamentos basados en escritos ancestrales espurios.

\section{DISCUSIÓN Y CONCLUSIONES}

En la actualidad, casi todas las colecciones precolombinas alojadas en museos internacionales poseen un porcentaje importante de piezas falsificadas (Bruhns \& Kelker 2010, Stanish 2009). Más allá de desmitificar el pasado, el estudio de falsificaciones y sus interpretaciones nos abre una importante ventana al estudio del contexto académico de una época, los debates intelectuales, las redes de coleccionistas y comerciantes de antigüedades, junto con los criterios curatoriales de las instituciones museográficas. El cómo estas falsificaciones han llegado a colecciones museográficas es también un reflejo de concepciones preconcebidas, que nos informan sobre la falibilidad de los expertos (Jones 1990: 11), en muchos casos, por la imposibilidad de conocer en profundidad la cultura material prehispánica de cada territorio (Bruhns \& Kelker 2010). Las falsificaciones son, por tanto, un aspecto importante a tener en cuenta en la construcción de la historia de los museos. Como señala Alberti (2009), los museos también se construyen basándose en la historia de la gente y de sus relaciones, de todos aquellos esfuerzos que sostienen la institución y sus colecciones, pero también de sus conflictos. A pesar de que los investigadores que sucedieron a Latcham constataron que la colección era falsificada, posiblemente pesó más la reputación institucional a la hora de decidir desmitificar tales artefactos y las interpretaciones generadas a partir de ellos. Por tal motivo, el hecho jamás fue público. 
En las piezas de alfarería descritas por Latcham, la presencia de motivos iconográficos Tiwanaku mezclados con Nazca es evidente, lo cual lleva al autor a profundizar más en sus interpretaciones de la existencia de una cultura primigenia andina, extrapolando de modo radical los planteamientos de Julio Tello, en vez de tomar otra vía y dudar de la autenticidad de la colección. En tal sentido, antes que poner en tela de juicio su prestigio académico, Latcham desarrolla más y más su interpretación, llegando a publicar cuatro artículos al respecto, siendo cada uno más especulativo que el anterior. La publicación posterior de un libro de aventuras demuestra la invención de una realidad, que escapa al rubro de sus publicaciones científicas.

Para Nieto-Galán (2011), ciencia y literatura comparten lugares comunes, marcos conceptuales y aspectos de una sociedad determinada. Durante el siglo $\mathrm{xx}$, diversos autores incorporaron aspectos del conocimiento científico en sus propias creaciones, y desde esa perspectiva podría entenderse el libro de Latcham, quien también se encuentra en un momento histórico donde los científicos y los medios de masas tenían cada vez una mayor interrelación. Es así como sobre el libro del tesoro de los piratas de Guayacán cabe la pregunta si dicha invención de la realidad corresponde a un esfuerzo deliberado de Latcham de falsear un relato basado en el encanto y fascinación sobre los misterios de escrituras ancestrales, o bien es el reflejo de un nuevo engaño debido a su interés por los escritos antiguos. Lo único que podemos afirmar es que, al haber revisado toda la documentación profesional y personal de Latcham presente en el Museo Nacional de Historia Natural, no ha sido posible encontrar ninguna evidencia que confirme alguno de los hechos descritos en dicho libro de piratas.

Como señalamos, el libro de Latcham tiene muchos elementos de las novelas de aventuras de la época e incluso es posible establecer ciertas similitudes en el estilo con las novelas de Harold T. Wilkins, escritas en el mismo período. Las novelas de Wilkins también se acompañan de fotografías y dibujos que buscaban dar validez y veracidad a sus argumentos, poniendo el centro de la atención en los misterios sin resolver. En The mysteries of ancient South America (1946), Wilkins aborda el tema de la desaparecida Atlántida y baraja teorías sobre su existencia. Para ello utiliza como fuentes a los cronistas de Indias que escucharon sobre estas leyendas en los siglos xvi y xVII, y una interpretación acrítica del pasado basada en un hiperdifusionismo cultural. Para el caso de la obra de Latcham sobre los piratas de Guayacán, el hecho de que se plantee en el título del libro la frase "relación verídica", le ha dado un reconocimiento social como fuente histórica legítima para argumentar, entre otros temas, la existencia de la asociación pirata de la Hermandad de la Bandera Negra y la presencia de piratas hebreos en Chile. Por tanto, no estamos frente a la historia de una simple falsificación de piezas prehispánicas. A lo largo de este artículo, identificamos un complejo entramado de situaciones que nos lleva de una falsificación de cultura material a la construcción de una realidad histórica ficticia, en un primer momento como un sesgo interpretativo y en un segundo momento, con un carácter al parecer más deliberado. Si bien, nunca sabremos si Latcham asumió personalmente este libro como una obra de ficción o no, lo relevante es el tono acrítico con que se ha tomado su obra, la cual sigue al día de hoy siendo considerada como histórica, teniendo un gran impacto social.

En conclusión, este artículo nos muestra cómo los marcos interpretativos académicos de la época, la reputación profesional y el aislamiento intelectual de Latcham, lo llevaron a generar una construcción de conocimiento e interpretaciones cada vez menos plausibles, estrechando los límites de la evidencia material arqueológica que poseía. Las falsificaciones ponen a prueba la falibilidad de los expertos y son difíciles de objetar cuando hay intereses académicos comprometidos. Hasta cierto punto, Latcham prueba con el libro de los piratas de Guayacán que puede prescindir completamente de la cultura material para generar una interpretación histórica verosímil y ad-hoc, simplemente fabricando las fuentes de interpretación. Por ello, resulta interesante que tal inspiración provenga del tema sobre el desciframiento de antiguas escrituras, basado en su mala experiencia académica previa. La paradoja es que el éxito que no logró al analizar una colección arqueológica "material", lo obtuvo finalmente al crear una "historia", basada en la ficción.

Agradecimientos Especialmente al Museo Nacional de Historia Natural de Chile. Este artículo se realizó en colaboración con el proyecto Fondecyt Iniciación No 11170033: "Antigüedades y naturaleza. Circulación interoceánica de objetos en los primeros gabinetes de historia natural como estrategia de posicionamiento de la ciencia en Chile". 


\section{NOTAS}

${ }^{1}$ En el prólogo de la edición de 2018, Hugo Zepeda afirma que Manuel Castro sería el nombre que Latcham inventó con el fin de proteger la identidad del verdadero buscador, Maximiliano Cortés.

${ }^{2}$ Ver por ejemplo: Secret lives of interns: ahoy vey!: $<$ http://jewishmuseummd.org/2010/08/secret-lives-ofinterns-ahoy-vey/> [consultado: 28-12-2019]; Los piratas judíos de Jamaica: <https://esefarad.com/?p=11990; http:// www.jewishsphere.com/Directory/FamousJewishPirates. html> [consultado: 02-11-2019]; Jewish Pirates/Privateers against the Catholic Empires: <http://www.jewishwikipedia. info/jewish_pirates.html> [consultado: 05-11-2019]; Jewish history 1600-1609: <http://www.jewishhistory.org.il/history. php? startyear $=1600 \&$ endyear $=1609>$ [consultado: 05-11-2019].

3 Ver, por ejemplo: Chile: país oceánico (Badal et al. 2005); Selkirk Robinson: el mito a tres siglos del desembarco del solitario en isla Robinson Crusoe (Brescia 2004); Raíces de la humanidad: las profecías bíblicas del fin del mundo (Guzmán 2011).

\section{REFERENCIAS}

AHA (Archivo Histórico Administrativo del Museo Nacional de Historia Natural).

Alberti, S. 2009. Nature and culture. Objects, disciplines and the Manchester Museum. Manchester: Manchester University Press.

BACHOFEN, J. 1967 (1861). Myth, religion and mother right. Princeton: Princeton University Press.

Badal, G., Balcells, G., Montanari, M., Santa Cruz, C. \& Altamirano, C. 2005. Chile: país oceánico. Santiago: Ocho Libros.

Bischof, H. 1998. Los orígenes de la civilización centroandina en la obra de Max Uhle. Indiana 15: 37-78.

BRESCIA, M. 2004. Selkirk Robinson: el mito a tres siglos del desembarco del solitario en la Isla Robinson Crusoe. Santiago: Mare Nostrum.

Bruhns, K. \& Kelker, N. 2010. Faking the ancient Andes. London-New York: Routledge.

García, G. 1729 [1607]. Origen de los indios del Nuevo Mundo e Indias Occidentales. Madrid: Imprenta Francisco Martínez Abad.

GuZMÁN, E. 2011. Raíces de la humanidad: las profecías bíblicas del fin del mundo. Bloomington: Palibrio.

Jones, M. 1990. Fake? The art of deception. London: British Museum Publications.

La Nación. 1929. Aviso de compra de antigüedades. Viernes 13 de septiembre: 31 .

Latcham, R. 1929a. Figuras que parecen geroglifos, en la alfarería Proto-Nazca. Boletín del Museo Nacional de Historia Natural 12: 93-101.
Latcham, R. 1929b. La leyenda de los Césares. Sus orígenes y su evolución. Revista Chilena de Historia y Geografía 64: 193-254.

Latcham, R. 1933. Alfarería de nuevo tipo, del valle de Ica (Perú). Revista Chilena de Historia Natural 37: 49-65.

Latcham, R. 1934. Alfarería arcaica de Ica. Revista Chilena de Historia Natural 38: 59-64.

Latcham, R. 1935. Alfarería de Ica (Perú). Revista Chilena de Historia Natural 39: 9-15.

Latcham, R. 1935b. El tesoro de los piratas de Guayacán. Relación verídica. Santiago: Nascimento.

Latcham, R. 1976. El tesoro de los piratas de Guayacán. Relación verídica. Santiago: Nascimiento.

LATCHAM, R. 2018. El tesoro de los piratas de Guayacán. Relación verídica. Prólogo de Hugo Zepeda Coll. Santiago: Hueders.

MartíneZ, J. 2011. Arte y culto. El poder de la imagen religiosa. Santiago: Dirección de Bibliotecas, Archivos y Museos.

Meltzer, M. 2001. Piracy and plunder: a murderous business. New York: Dutton Children's Books.

Mora, G. 2011. Falsarios y el concepto de lo falso: pasado y presente. De las antiguas excavaciones al coleccionismo privado y el comercio de antigüedades. In ¿Hombres $o$ dioses? Una nueva mirada de la escultura del mundo ibérico, pp. 261-278. Alcalá de Henares-Madrid: Museo Arqueológico Regional.

Morgan, L. 1985 (1877). Ancient Society. Tucson: University of Arizona Press.

Murray, T. 2007. Rethinking antiquarianism. Bulletin of the History of Archaeology 17 (2): 14-22.

Murray, T. 2013. Antiquarianism of and in preliterate societies. Colonial and postcolonial contexts. In World antiquarianism. Comparative perspectives, A. Schnapp, Ed., pp. 11-35. Los Angeles: Getty Research Institute.

Nieto-Galán, A. 2011. Los públicos de la ciencia. Expertos y profanos a través de la historia. Madrid: Marcial Pons Historia.

Orellana, M. 1996. Historia de la arqueología en Chile (18421990). Santiago: Bravo y Allende.

Orgambide, P. 1977. Aventuras de Edmund Ziller en tierras del Nuevo Mundo. Barcelona: Grijalbo.

SALOMon, F. 2013. The twisting paths of recall: khipu (Andean cord notation) as artifact. In Writing as material practice, K. Piquette \& R. Whitehouse, Eds., pp. 15-43. London: Ubiquity Press.

Stanish, C. 2009. Forging ahead. Archaeology 62 (3).

Urton, G. 2014. From Middle Horizon cord-keeping to the rise of Inka khipus in the central Andes. Antiquity 88 (339): 205-221.

URTON, G. 2017. Inka history in knots. Austin: University of Texas Press.

WiLkins, H. 1934. Modern buried treasure hunters. London: Philip Allan.

WiLkins, H. 1945. Mysteries of ancient South America. London: Rider and Co. 